Daimon. Revista Internacional de Filosofía, n ${ }^{\circ} 85$ (2022), pp. 161-175

ISSN: 1130-0507 (papel) y 1989-4651 (electrónico)

http://dx.doi.org/10.6018/daimon.410401

Licencia Creative Commons Reconocimiento-NoComercial-SinObraDerivada 3.0 España (texto legal). Se pueden copiar, usar, difundir, transmitir y exponer públicamente, siempre que: i) se cite la autoría y la fuente original de su publicación (revista, editorial y URL de la obra); ii) no se usen para fines comerciales; iii) se mencione la existencia y especificaciones de esta licencia de uso.

(c) (1) (9) $\odot$

\title{
Filipo II de Macedonia: el primer europeo. Asia y Europa como conceptos políticos en la Grecia clásica
}

\author{
Phillip II of Macedon: The First European. \\ Asia and Europe as Political Concepts in Classical Greece
}

CÉSAR SIERRA MARTÍN*

\begin{abstract}
Resumen: El presente artículo tiene como objetivo analizar la evolución histórica y cultural de Europa y Asia como términos políticos en la Grecia clásica. Para ello, abordaremos fuentes de diversa índole como Esquilo, Heródoto, el escrito hipocrático Aires, aguas y lugares y el orador Isócrates. Partiremos de la equiparación inicial entre Europa (= Grecia) y Asia (= Persia) hasta alcanzar la propuesta de Isócrates de considerar a Filipo como un líder europeo.
\end{abstract}

Palabras clave: Europa, Asia, Grecia clásica, Filipo de Macedonia.

\begin{abstract}
The aim of this paper is to analyse the historical and cultural evolution of Europe and Asia considered as a political terms in Classical Greece. In order to achieve this objective, we will address several primary sources such as Aeschylus' Persians, Herodotus, the Hippocratic treatise Airs, Waters and Places and, finally, Isocrates. We will start from the Greek integration between Europe (= Greece) and Asia (= Persian Empire) in order to reach the isocratic proposal which considers Phillip of Macedon as a European leader.
\end{abstract}

Keywords: Europe, Asia, Classical Greece, Phillip of Macedon.

\section{Encuadre y objetivo del trabajo}

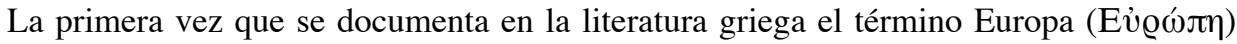
como realidad geográfica es en el Himno a Apolo (252) ${ }^{1}$. Se trata de una composición poética atribuida tradicionalmente al propio Homero y que, en cualquier caso, debemos situar en los albores de la producción literaria griega (s. VIII a.C.) ${ }^{2}$. Asimismo, documentamos el término en el poeta beocio Hesíodo (s. VIII a.C.; Hes. Th. 359-359) en cuya enumeración de

Recibido: 16/01/2020. Aceptado: 03/07/2020.

* Profesor del área de Historia antigua de la Universidad de Valencia (cesar.sierra@uv.es). Líneas de investigación: historiografía clásica, medicina antigua, historiografía moderna sobre la antigüedad. Este artículo se ha realizado en el marco del proyecto financiado por el Ministerio de Ciencia e innovación: "Antigüedad, nacionalismos e identidades complejas: Aproximación desde Europa y América latina (1789-1989); HAR 2016-76940P" dirigido por el prof. Antonio Duplá (Universidad del País Vasco).

1 El dato recogido en diccionario de referencia A Greek English Lexicon; s.v. Liddell-Scott (1996, 731).

2 Más detalles sobre la discutida autoría, composición y datación del poema en Bernabé (2001, 53-73). 


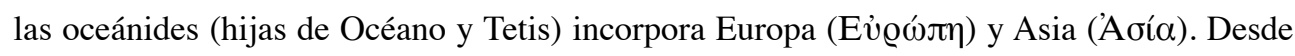
un inicio, la reflexión sobre los mentados términos en la cultura griega adopta un enfoque poliédrico: mitológico/religioso, cultural/lingüístico, geográfico y político; sirva lo anterior como un sencillo ejemplo que muestra los diferentes caminos que puede tomar el análisis de los conceptos 'Asia' y 'Europa'. En la siguiente reflexión centraremos la atención en la dimensión política del término Europa y en su evolución histórica durante el siglo V a.C.

\section{Introducción}

En época arcaica, la idea de Europa parte de una matriz clara, la Grecia continental, desde donde se construyen el resto de realidades geográficas, culturales y políticas a medida que los griegos avanzan en el conocimiento del territorio que los circunda. Un ejemplo claro de este proceso lo tendríamos en la consideración que merecen los confines del mundo conocido en el imaginario griego. Así, partiendo de obras de época arcaica que ensueñan regiones míticas, como la isla de Esqueria en la Odisea (s. VI a.C.; Hom. Od. VI. 1), quizás localizable en el mar Jónico, o el célebre Jardín de las Hespérides, identificado por Hesíodo (s. VIII a.C.) y situado en los confines occidentales, (Hes. Th.617-520); pasamos a la construcción de una geografía empírica con autores como Hecateo de Mileto o el propio Heródoto de Halicarnaso $^{3}$. Serán, precisamente, los mentados autores quienes desarrollarán una imagen

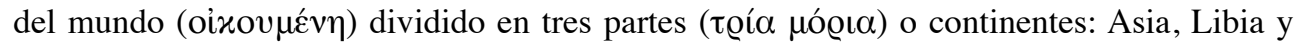
Europa (Hdt. II. 16) ${ }^{4}$. Así pues, a medida que se exploran estos confines por navegantes y aventureros griegos, dichas regiones fantásticas se desplazan en el imaginario hacia lugares todavía más recónditos e inexplorados. Todo ello alimenta sobremanera el discurso centro/ periferia, que en época clásica experimentará una profunda renovación al abrigo de las guerras médicas (490 y 480 a.C.) y, sobre todo, la expedición de Alejandro.

Por otro lado y como se ha dicho anteriormente, el término Asia ('A ó́ $\alpha$ ) queda atestiguado desde Hesíodo (Th. 359), designando a una Oceánide en un contexto geográfico definido por un mundo mítico sin contornos reales definidos. No se aprecia en este momento un tono peyorativo de 'lo asiático' aunque, en relativamente poco tiempo, la tendencia de los griegos virará hacia la polarización de las relaciones entre Asia y Europa. A nivel político, la progresiva degradación del término 'Asia' puede seguirse en el poeta Arquíloco de Paros (mitad del s. VII a.C.), quien introduce diversos tópicos que tendrán un enorme éxito histórico:

No me importan los asuntos de Giges, rico en oro, ni me apresó todavía la envidia, ni miro con celos

obras de dioses, ni busco la gran tiranía;

está muy lejos de mis ojos (frag. 19 West) ${ }^{5}$.

3 Ambos autores representan el tránsito del mundo intelectual arcaico al clásico gracias al método de la iơo@í (o investigación) que supuso un salto cualitativo en la construcción del conocimiento, en definitiva, un giro epistemológico; $v$. Fowler (2001) y Lloyd (2008 [2002], 17 ss.).

4 División que se remonta a Hecateo de Mileto; $v$. Asheri/Lloyd/Corcella (2007, 253).

5 Seguimos la traducción propuesta por Molina. J. 2011: Arquíloco. Fragmentos, Monterrey: Universidad Autónoma de Nuevo León. Véase comentario a este pasaje en Gómez Espelosín (2013, 133 ss.). 
El anterior testimonio acuña por vez primera la figura política del tirano ( $u$ @avvos), cuya vinculación con el reino de Lidia a través de su rey Giges ha suscitado una gran controversia por la posibilidad de que el término tuviera un origen asiático ${ }^{6}$. Por sí misma, la anterior cuestión es muy relevante para el tema que nos ocupa pero, por añadidura, Arquíloco introduce la idea de un reino de Lidia rico en oro $^{7}$. Esta idea de opulencia e, incluso, el tópico de una vida muelle (asiática) tendrá un largo recorrido en la historia de Europa. Con todo, los escuetos testimonios del poeta pario no permiten inferir mucho más sobre los términos políticos en qué se valoraba Asia ${ }^{8}$.

En cambio, con el tiempo Asia y Europa se introducen progresivamente en el discurso étnico y cultural dominado por el binomio griego/bárbaro. En este sentido, cabe decir que la

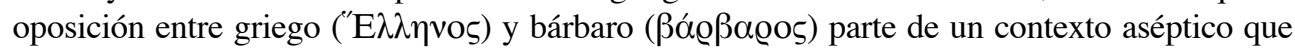
denota distintas formas de hablar o comunicarse ${ }^{9}$. De nuevo, será en el transcurso del conflicto entre griegos y persas cuando esta relación se polarice hasta el extremo de considerarse términos antagónicos. A partir de las guerras médicas, con frecuencia se concebirá en la literatura de todo tipo una Europa griega frente a un Asia bárbara ${ }^{10}$. Todo ello marca sobremanera la producción intelectual, con obras como la de Heródoto en cuyo célebre proemio se expone:

Esta es la exposición del resultado de las investigaciones de Heródoto de Halicarnaso para que, con el tiempo, los hechos humanos no queden en el olvido y que las notables y singulares empresas realizadas, respectivamente, por griegos y bárbaros $-\mathrm{y}$, en especial, el motivo de su mutuo enfrentamiento- queden sin realce.

Hdt. I. 1. $0^{11}$

Se deduce del testimonio anterior que griegos y bárbaros representan mundos opuestos y que, a su vez, protagonizan las obras $\left(\mathrm{\varepsilon}^{\mathrm{Q}} \gamma \alpha\right)$ entendidas como acciones de guerra ${ }^{12}$. Asimismo, la oposición griego/bárbaro se extenderá casi en idénticos términos a la cuestión Europa/Asia, generando una confrontación que perdura hasta nuestros días. Por este motivo, el conocimiento griego producirá literatura de muy diversa índole cuyos temas e intereses se orientarán hacia la fundamentación de la oposición entre Europa y Asia. Naturalmente, en la época todo ello tiene una lectura geográfica, política, étnica, cultural y científica. Por consiguiente, en las próximas líneas abordaremos la construcción de la oposición entre Europa y Asia a través de fuentes primarias de diferente naturaleza como son la tragedia (Esquilo, Los persas), la historiografía (Heródoto) y la medicina (el escrito hipocrático Aires,

6 Cuestión rebatida brillantemente por Santo Mazzarino, quien sostuvo que la tiranía era una forma de gobierno genuinamente griega y la interpretación de su origen asiático respondía a prejuicios antiguos y modernos; Mazzarino (1989 [1947], 193-199). Una aproximación más reciente a la cuestión la hallamos en Plácido (2007).

7 Parece que el tópico tiene continuidad en el fragmento 227 donde, posiblemente, identifica a Giges como amo

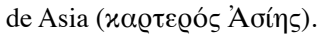

8 Más allá de un cierto desdén hacia la riqueza de Giges como apunta Gómez Espelosín (2013, 133).

9 Siguiendo a la prof. Santiago, la primera anotación del término $\beta \alpha ́ \varrho \beta \alpha \varrho o \varsigma$ tiene lugar en la Ilíada (II. 867) en relación a la forma de hablar distinta a la griega de los pueblos carios; Santiago $(1998,35)$.

10 Excepción hecha de los griegos que habitaban Asia menor.

11 En adelante seguimos la traducción de C. Schrader 2000: Heródoto. Historia, Madrid: Gredos.

12 Digamos que capitalizaron las acciones dignas de ser contadas. Sobre este pasaje resulta de interés la valoración de Marincola $(2001,26-27)$. 
aguas y lugares $)^{13}$. Documentos relacionados entre sí precisamente por la visión que aportan de ambas realidades geográficas y que, a la sazón, cubren un amplio arco cronológico del siglo V a.C. que permitirá apreciar la evolución de la mentalidad griega en relación al continente vecino. Finalmente, concluiremos con una breve reflexión sobre la influencia de estas fuentes en el antagonismo Asia/Europa que marcará los inicios del siglo IV a.C. con las valoraciones de Isócrates.

\section{El origen del conflicto: Asia y Europa tras las guerras médicas}

\section{3. a) La valoración de Esquilo en Los Persas}

La tragedia titulada Los Persas se estrenó aproximadamente ocho años después de la segunda guerra médica y, quizás, presenta por primera vez los continentes de Asia y Europa como realidades en permanente conflicto. Como es bien sabido, la obra es una exaltación de la victoria griega sobre los persas, presentada al público como una contienda entre dos formas de entender la vida y la política. El elemento central de la obra es bien conocido: Atosa (madre de Jerjes y esposa de Darío) espera noticias sobre el resultado de la campaña bélica en Grecia. En el transcurso de la acción dramática, se muestra a la reina atribulada por un sueño que la previene del resultado de la guerra ${ }^{14}$. Los sucesos siguientes confirman las inquietudes de la reina y el público recibe la noticia de la derrota persa por medio de un mensajero, en primera instancia, y finalmente por boca de Jerjes.

Para lo que aquí nos atañe, Los Persas introduce la idea de una asimilación entre Asia, como continente, y el Imperio persa como estructura política. Dicho de otro modo, se equipara Persia con Asia en virtud de la extraordinaria extensión del imperio Aqueménida. Todo ello queda perfectamente fijado desde el inicio cuando se representa el poder de Jerjes como sigue: $Y$ de toda Asia les sigue la gente armada de espada que el Rey ha hecho ir con orden severa (Aesch. Pers. 55) ${ }^{15}$. Así pues, el rey persa queda definido como señor de toda Asia mientras que la pólis (y su mundo) representa la independencia de Grecia (Europa) frente al ataque. Por así decirlo, la situación toma la forma de una lucha entre la tiránica Persia (retomando la figura de Giges) y la Grecia libre (encabezada por la democrática Atenas) ${ }^{16}$; dicha imagen se materializa en el momento en que Atosa pregunta al corifeo sobre quiénes son los atenienses y cómo se gobiernan:

13 Respectivamente, la tragedia de Los Persas de Esquilo es una de las obras cuya cronología se conoce mejor 472 a.C., siendo corego un joven Pericles (Rodríguez Adrados 2000, XV); La actividad intelectual de Heródoto alcanzó los prolegómenos de la guerra del Peloponeso (c. 430 a.C.; Asheri/Lloyd/Corcella 2007, 5 ss.) y el escrito hipocrático Aires, aguas y lugares, cuya datación se ubica en el último tercio del siglo; Jouanna (1996, 81-82).

14 El sueño de Atosa es una licencia poética para otorgar vivacidad al relato que Esquilo quería proyectar sobre el público; véase Harris $(2009,96)$.

15 En adelante, seguimos la traducción de Perea Morales, B. 2000: Esquilo. Tragedias, Madrid: Gredos.

16 La obra de Esquilo exalta la victoria griega, en general, y encumbra a la democrática Atenas, en particular. Dicho panegírico alcanzará su punto culminante en época de Tucídides y toma forma en la 'Oración fúnebre' de Pericles (Th. II. 35-46), que emplaza a la ciudad de Atenas como modelo de Grecia y al ateniense como arquetipo de ciudadano; v. Hermosa $2019: 137-138$. 
Reina - ¿Y qué Rey está sobre ellos y manda su ejército?

Corifeo - No se llaman esclavos ni súbditos de ningún hombre.

Aesch. Pers. 240

El efecto propagandístico de la obra adquiere aquí toda su claridad y, además, sirve para exaltar los gobiernos libres griegos frente a la monárquica Persia. Como bien indica el texto,

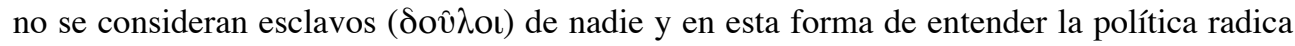
precisamente su éxito ${ }^{17}$. En toda la obra se contrapone una Persia (=Asia) unida sólo por la monarquía/tiranía de Jerjes frente a una Grecia (= Europa) libre y con lazos más sólidos. El esquema anterior queda perfectamente definido en la descripción de la batalla de Salamina donde, según el mensajero persa, se podía oír en el campo de batalla la siguiente arenga:

Al mismo tiempo podía oírse un clamor: "Adelante, hijos de los griegos, libertad a la patria. Libertad a vuestros hijos, a vuestras mujeres, los templos de los dioses de vuestra estirpe y las tumbas de vuestros abuelos. Ahora es el combate por todo eso". Aesch. Pers. 401-405

Aparecen en el testimonio anterior conceptos que ayudan a distinguir las claves de la

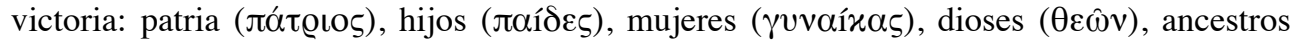

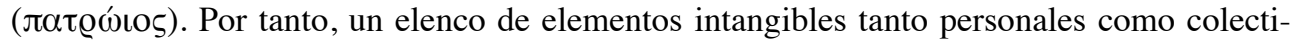
vos, que definen una comunidad libre, étnica y patriótica que lucha por la supervivencia de una forma de vida concreta: la pólis. Por paradójico que parezca, la identidad étnica griega se vio reforzada gracias a la amenaza de los persas ${ }^{18}$. Lo anterior encuentra un interesante paralelismo en la célebre definición, diríamos incluso canónica, que realiza Heródoto sobre

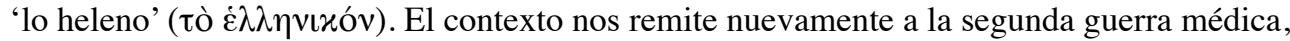
cuando existían dudas sobre la lealtad ateniense hacia la alianza griega en vista de la desidia espartana para defender el Ática del ataque de Jerjes. Como decíamos, en esta tesitura se dibuja una adscripción de los atenienses a la causa griega en virtud del respeto a los valores de una comunidad étnica que se expresa en los siguientes términos:

En efecto, muchas e importantes razones son las que nos impiden obrar así [traicionar a la causa griega], ni aunque quisiéramos: las primeras y más importantes, las estatuas y las mansiones de los dioses incendiadas y arrasadas, a las que obligación nuestra es vengarlas en la mayor medida posible antes que llegar a un acuerdo con el que hizo tales cosas; por otra parte, lo helénico - que es la misma sangre y la misma lengua, templos comunes de los dioses, y sacrificios, y costumbres semejantes - , de lo que no estaría bien que fueran traidores los atenienses.

Hdt. VIII.144.219

17 Nótese como la cuestión de la esclavitud reaparece hacia el último tercio de la obra a colación del simbólico episodio de Jerjes esclavizando al Helesponto (Aesch. Pers. 745-747).

18 Sobre la construcción de la identidad política en esta época y, en concreto, de la democracia ateniense véase Quesada (2008).

19 El texto entre corchetes es nuestro como glosa para situar al lector en el contexto. 
Se trata de un pasaje muy estudiado por la crítica moderna que emplaza la construcción de lo griego como una congregación de valores tales como: lengua, religión, costumbres, etc. Destaca sobremanera la identificación de una comunidad de sangre (ő $\mu \alpha \mu \rho \varsigma)$, lo cual viene a proporcionar una base biológica (y no sólo cultural) a la identidad étnica griega de época clásica ${ }^{20}$.

\section{3. b) La valoración historiográfica de Heródoto}

Por este motivo Heródoto presenta el conflicto entre griegos y persas como un choque de civilizaciones. Así, al inicio de la Historia se realiza una arqueología del conflicto grecopersa donde la guerra de Troya supone el inicio de las hostilidades entre ambos (Hdt. I. 4) ${ }^{21}$. Sobre este asunto, Heródoto refiere las diferentes versiones sobre el origen del conflicto que unos y otros ofrecían en su época, incluso relatando la posición persa que pondera la insalvable división entre Asia y Europa:

A raíz de entonces, siempre han creído que el pueblo griego era su enemigo; pues los persas reivindican como algo propio Asia y los pueblos bárbaros que la habitan, y consideran que Europa y el mundo griego es algo aparte.

Hdt. I. 4.4

Nótese cómo se definen los continentes según áreas de influencia política y cultural ${ }^{22}$ donde Persia se equipara a toda Asia y, no sin pretensiones, se asimila Europa con Grecia. Todo ello concuerda con el esquema propuesto por Esquilo e, incluso, se emplean recursos literarios similares para explicar el devenir de la guerra. Por ejemplo, si para dar vida a su relato Esquilo recurre a la visión onírica de Atosa; Heródoto introduce lo siguiente en relación al fundador del imperio, Ciro II el grande, durante su expedición contra los masagetas:

Una vez atravesado el Araxes, Ciro, al caer la noche y mientras dormía en el país de los masagetas, tuvo la siguiente visión. Creyó ver en sueños al mayor de los hijos de Histaspes con alas en los hombros y que, con la sombra de una de ellas, cubría Asia y que, con la otra, Europa.

Hdt. I. 209. 1-2

El hijo de Histaspes en cuestión es Darío y la profecía afirma que heredará el imperio y, por tanto, que la muerte del propio Ciro estaba próxima. Aunando ahora los ejemplos de Esquilo y Heródoto, apreciamos que el destino se presenta ante los persas como una fuerza ineludible que les conduce al conflicto con Grecia. En el último caso descrito, el

20 El uso del término en Heródoto no se reduce a este pasaje: Hdt. I. 4; I.60; V. 49. 3; VII. 139 y VII. 145; v. Hall $(2002,35)$ y Zacharia $(2008,21)$.

21 Otros autores como Tucídides (I. 9) o Isócrates (Panatenaico 80) visualizan las relaciones entre griegos y persas de la misma forma; $v$. de Romilly $(1992,7)$.

22 Algo que ya se apuntaba en el proemio unas pocas líneas antes. 
sueño sugiere que Darío dominará Europa, lo cual intenta sin éxito, mientras que la visión de Atosa anticipa el fracaso de Jerjes ${ }^{23}$.

Avanzando ahora hacia el terreno de la geografía, Heródoto muestra una visión mucho más amplia de Europa y Asia. En este sentido, el discurso del historiador abandona el determinismo anterior y se inserta en las investigaciones acometidas por la logografía jonia. La gran diferencia respecto a la logografía viene dada por el mayor interés que concede Heródoto a la continuidad de las culturas en el territorio en detrimento de los accidentes geográficos ${ }^{24}$. En este sentido, Europa y Asia entran en el debate alrededor de los límites del mundo, evidenciando que Grecia era solo una pequeña porción de Europa. Ello toma forma en la descripción de la región habitada por los celtas, la más occidental de Europa (Hdt. II. 33) ${ }^{25}$. Asimismo, resulta muy interesante detenerse en el detalle de la descripción de Asia y Europa, que abandona el simplismo mostrado anteriormente (Hdt. IV. 36-42). Aquí, el autor enumera los diferentes pueblos que habitaban ambos continentes y los límites o contornos cuyo conocimiento, admite Heródoto, era precario ${ }^{26}$. De la exploración de los confines surgirá el interés por regiones extremas como la India, el país de los etíopes (África subsahariana), el fabuloso pueblo de los hiperbóreos o las regiones más allá de las Columnas de Heracles (estrecho de Gibraltar). A todos estos lugares se les asociarán riquezas, recursos y costumbres que entran de lleno en terreno paradoxográfico lo cual embelesará a los griegos durante generaciones ${ }^{27}$. A modo de conclusión, el relato de Heródoto en relación a Europa y Asia presenta dos caminos: por un lado, abunda en el plano político sobre las consideraciones que Esquilo había puesto sobre la mesa y, por otro lado, amplía la información geográfica sobre ambos continentes en sintonía con los logógrafos. En otros términos, Esquilo realiza una valoración cultural y política mientras Heródoto apuesta por un análisis cultural, político, etnográfico y geográfico. En el esquema anterior falta la tercera vía que, en cierta medida, reúne las anteriores: el determinismo ambiental desarrollado por la medicina.

\section{3 c) El determinismo climático de Aires, aguas y lugares}

Recogiendo el anterior testigo, el escrito hipocrático Aires, aguas y lugares (= Aër.) es conocido por enunciar la 'teoría climática', esto es, que la biodiversidad de la Tierra viene dada por el clima y la variación estacional. Además, también postula que el clima es responsable del carácter e inteligencia de los seres humanos, lo cual es una idea que domina todo el escrito. No obstante, los temas y contenidos de Aër. son muy diversos y muy notables las conexiones con la etnografía y la geografía, aproximándose a la logografía jonia y al propio Heródoto 28 .

23 Véase un análisis pormenorizado y más ejemplos en Grethlein (2009, 202 ss.).

24 Cuestión muy bien trabajada en Gómez Espelosín $(2000,188)$.

25 Acerca de los contornos de Europa en la geografía griega de la primera mitad del V a.C., véase Albaladejo (2005), con especial mención a los testimonios de Píndaro y Heródoto.

26 Amplíese la discusión sobre este asunto en Romm (1992, 82 ss.).

27 La problemática acerca del conocimiento de los confines del mundo en la obra de Heródoto puede seguirse en la citada obra de Romm (1992) y también en Albaladejo (2008).

28 La deuda intelectual de Aër. con los presocráticos, en especial Alcmeón, y su conexión con Heródoto ha sido bien advertida por López Férez $(1984,104)$. 
El escrito se divide en dos partes perfectamente delimitadas, en los primeros once capítulos se aborda la relación entre ser humano y medio ambiente, analizando los efectos de los cambios de estación, la orientación de las ciudades respecto a los vientos, los tipos e influencia de las aguas en la salud humana. Todo ello tiene el objetivo declarado de proporcionar una base de conocimiento sólida al médico itinerante que llega por primera vez a una ciudad $^{29}$. Los trece restantes capítulos ofrecen un interesante giro hacia temas etnográficos, geográficos y políticos; concretamente se plantea una comparación entre Asia y Europa con la premisa de que difieren en todos los aspectos (Hp. Aër. 12). A partir de aquí se extiende una reflexión conocida por la mayor parte de especialistas pero muy poco explorada en sus consecuencias últimas ${ }^{30}$. Según el escrito, las personas que habitan bajo un clima estacionalmente monótono son físicamente muy parecidos entre sí, más altos y apuestos pero también más indolentes y cobardes. En cambio, quienes ocupan territorios con fuertes variaciones estacionales son rudos, aguerridos e irreflexivos (Hp. Aër. 12-13). Por así decirlo, el clima asiático es propicio para el desarrollo de plantas y animales magníficos; también lógicamente para generar seres humanos de formidable aspecto y salud. Sin duda todo ello tiene una lectura política interesante que el escrito presenta como sigue:

Respecto a la indolencia y cobardía de sus habitantes, y, concretamente, de que los asiáticos sean menos belicosos que los europeos y de carácter más pacífico, los responsables son, sobre todo, las estaciones, porque no ocasionan grandes cambios, ni en calor ni en frío, sino que son parecidas. Efectivamente, no se producen conmociones de la mente ni perturbación violenta del cuerpo, motivos por los que es natural que el carácter se vuelva rudo y tenga un componente mayor de irreflexión y apasionamiento que cuando está siempre en las mismas circunstancias. [...] Por esos motivos me parece a mí que carece de vigor el pueblo asiático y, además, a causa de sus instituciones, pues la mayor parte de Asia está gobernada por reyes. Donde los hombres no son dueños de sí mismos ni independientes, sino que están bajo un señor, su preocupación no es cómo ejercitarse en las artes de la guerra, sino cómo dar la impresión de no ser aptos para el combate. [...] Con los méritos y hazañas que los vasallos realizan, los amos aumentan su poder y se encumbran, mientras que aquéllos obtienen como fruto los peligros y la muerte.

Hp. Aёr. $16^{31}$

Desde nuestro punto de vista, el pasaje sugiere que el cerebro es el centro de aptitudes propias del carácter humano como la valentía o la cobardía. Muy notablemente se debe

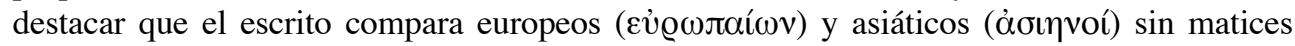
que nos introduzcan la diversidad de una y otra realidad geográfica. En este sentido, se

29 La elección de las ciudades donde los médicos prestaban sus servicios no era aleatoria, dependía de la demanda laboral y las posibilidades económicas de la ciudad; $v$. Chang (2005). Sobre la figura del médico itinerante resultan interesantes los testimonios epigráficos recogidos en Samama (2003, 25-27).

30 Las cuales son de vital importancia para comprender ciertos prejuicios sobre el carácter de las personas en función de la región climática de la que proceden. Ni qué decir tiene que dicho tópico llega con fuerza hasta nuestros días.

31 Seguimos la traducción de López Férez, J. A. 2000: Tratados hipocráticos, Madrid: Gredos. 
podría haber recurrido al binomio griego/bárbaro pero ello, a nuestro juicio, no evidenciaría los bloques que el escritor quería mostrar: en Europa también hay bárbaros. Por así decirlo, se debe mostrar ambos continentes como unidades antagónicas también a nivel ambiental. Retomando el texto, las bruscas variaciones estacionales producen que las personas tengan, digámoslo así, afectaciones en el cerebro que producen alteraciones de la inteligencia y el carácter. Abundando en este asunto, la medicina griega entendía que la naturaleza humana no era igual (ni equivalente) dado que, desde el exterior, podían modificarse las condiciones del cuerpo $^{32}$. De modo que las diferentes investigaciones sobre la naturaleza ( $\left.\phi u ́ \sigma \iota \varsigma\right)$ no condujeron hacia una teoría sobre la igualdad entre los seres humanos, lo cual constituye un fuerte condicionante en la génesis de la alteridad griega desde el pensamiento médico. Por decirlo llanamente: los griegos entendían que existían personas superiores por naturaleza. Ahora bien, esta ventaja inherente podía reducirse e incluso superarse con un adecuado y tenaz trabajo sobre las correctas costumbres (vó $\mu \mathrm{ol}$ ) que desarrollaban las virtudes del hombre ${ }^{33}$. Al abrigo del anterior argumento, el pasaje que estamos considerando constituye uno de los primeros ejemplos del debate entre naturaleza ( $\phi u ́ \sigma ı)$ y costumbre (vó $\mu \circ \varsigma$ ); dicho de otro modo, si la diversidad humana responde a criterios culturales o resulta una cuestión conforme natura

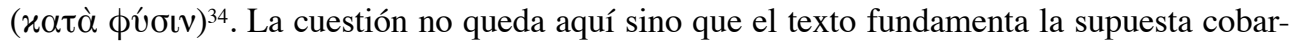
día asiática desde las instituciones políticas ${ }^{35}$ según la abundancia de monarquías, que es el gobierno enfermo por excelencia en la cultura griega clásica ${ }^{36}$. Así, en términos generales, el escrito hipocrático sugiere que existe un vínculo entre la climatología y la forma de gobierno que adopta una región ${ }^{37}$. El argumento se cierra reincidiendo sobre la naturaleza de los gobiernos asiáticos y enfatizando que allí donde sus habitantes no viven bajo una monarquía, se distinguen por su valor en el combate (Hp. Aër. 16. 5). No cabe duda de que el planteamiento anterior adquirirá gran relevancia entre los pensadores del siglo IV, como puede ser Platón cuando en Leyes razona sobre la mezquindad natural de fenicios y egipcios:

Porque tampoco, ¡Oh, Megilo y Clinias!, se os pase inadvertida una cosa en relación con los lugares, y es que los hay que aventajan a otros en cuanto a engendrar hombres mejores o peores, y que no se puede legislar prescindiendo de este hecho. En efecto, hay algunos de ellos que por los cambios de vientos, creo yo, o por los calores resultan favorables o bien desfavorables, y a otros les ocurre lo propio por las aguas,

32 Dependía de parámetros como la edad, el género, la alimentación, la complexión y el lugar de residencia; $v$. López Férez $(1984,115)$.

33 Se trata de un modelo de perfeccionamiento de la condición humana a través de las costumbres y la educación que tiene en la escuela socrática, notablemente Jenofonte y Platón, a uno de sus máximos paradigmas; $v$. O’Connor (2011) y, recientemente, Sierra (2018).

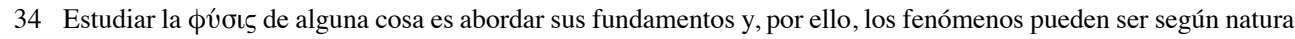

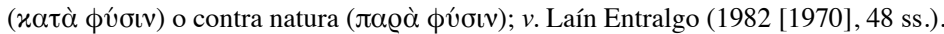

35 En el texto griego habla de leyes toù sópous, (las instituciones) mantenemos la traducción de J. A. López Férez porque responde bien al espíritu del argumento.

36 Pensamos que este planteamiento político está muy en sintonía con la reflexión que propone Heródoto sobre la mejor forma de gobierno en un debate ficticio entre los persas Ótanes, Magabizo y Darío (Hdt. III. 80. 1); $v$. Plácido (2007).

37 Cuestión muy bien advertida en Mas (2003, 103 ss.). 
y a otros por la alimentación misma producida por la tierra, que no solamente puede influir sobre los cuerpos en bueno o en mal sentido [...]

Pl. Leg. 747 d-e 38

Abundando sobre este mismo asunto tenemos al discípulo de Platón, Aristóteles, quien expone en Política los motivos de la diversidad humana como sigue:

Digamos ahora cuál debe ser el carácter natural de los ciudadanos. Más o menos podría comprenderse esto echando una ojeada a las ciudades griegas más famosas y a todo el mundo habitado para ver cómo se distribuyen en él los pueblos. Los que habitan en lugares fríos y en Europa están llenos de coraje, pero faltos de inteligencia y de técnica, por lo que viven más bien libres, pero sin organización política o incapacitados para mandar en sus vecinos. Los de Asia, en cambio, son inteligentes y de espíritu técnico, pero sin coraje, por lo que llevan una vida de sometimiento y esclavitud.

Arist. Pol. $1327 \mathrm{~b} 23-33^{39}$

Nótese la extraordinaria similitud de ambos testimonios con la propuesta del escrito hipocrático que, considerados en su conjunto, ofrecen los rudimentos de un pensamiento supremacista helénico (y europeo) frente a 'lo asiático' ${ }^{40}$. Al hilo del anterior argumento, se establece una gradación entre los diversos pueblos que habitan el planeta con los griegos en la cúspide. Por consiguiente, las impresiones de Aires, aguas y lugares suponen un punto de partida en este discurso supremacista a la par que un exponente de esa tercera vía que complementa a los discursos de Esquilo y Heródoto.

\section{Filipo II de Macedonia: Isócrates y el primer europeo}

Con todo lo dicho hasta aquí se percibe una cuestión central todavía no abordada ¿Qué se entiende por europeo en época clásica? La pregunta resulta pertinente habida cuenta de que, al parecer, nadie reclamaba tal 'privilegio'. En este sentido, un autor muy avezado en la teorización política de Europa fue el maestro de retórica Isócrates ${ }^{41}$. Como es bien sabido, Isócrates vivió a caballo entre el siglo $\mathrm{V}$ y IV y pudo ser testigo del desgaste que acumulaba Grecia tras décadas de conflictividad ${ }^{42}$. A menudo la historiografía moderna califica este periodo como 'crisis de la pólis' pero, en realidad, la pólis como organización política pervive incluso en época romana ${ }^{43}$. Con todo, conviene afirmar que, tras Queronea (338

38 Seguimos la traducción de Pabón, J. M. 2008: Platón. Las leyes, Madrid: Alianza.

39 Seguimos la traducción de García Valdés, M. 2000: Aristóteles. Política, Madrid: Gredos.

40 Conexión bien advertida por Isaac (2004, 69 ss.).

41 En este punto nos adherimos a las atinadas observaciones Jacqueline de Romilly $(1992,2)$.

42 Amplíese el contexto en Plácido (2017, 87-101).

43 La pólis griega experimentará una evolución profunda hasta adaptarse a la realidad romana como bien indica Cortés Copete (2005). 
a.C.), los griegos pierden su autonomía definitivamente ${ }^{44}$. Resulta cuanto menos paradójico que Isócrates, defensor en primera instancia de Filipo y detractor en su última fase, viviera hasta la pérdida de la libertad política en Grecia. En este momento, el debate alrededor de los términos griego/bárbaro y, respectivamente, Europa/Asia llegó a su máxima polarización. No en vano, el propio Isócrates defendió a lo largo de su obra una acendrada política panhelénica ${ }^{45}$. Para el rétor, lo más deseable era la concordia entre griegos y la unión contra el enemigo común: Persia (= Asia). Entrando en el detalle, Isócrates defiende inicialmente que la coalición panhelénica debía estar liderada por Atenas, que define como una comunidad culturalmente superior al resto. Téngase en cuenta lo anterior en su Panegírico, compuesto hacia el 380 a.C., donde trata de superar el ya citado $\tau$ ò $\dot{\varepsilon} \lambda \lambda \eta v \iota x o ́ v:$

Nuestra ciudad aventajó tanto a los demás hombres en el pensamiento y oratoria que sus discípulos han llegado a ser maestros de otros, y ha conseguido que el nombre de griegos se aplique no al linaje, sino a la inteligencia, y que se llame griegos más a los partícipes de nuestra educación que a los de nuestra misma sangre.

Isoc. Panegírico $50^{46}$

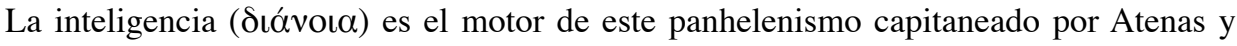
que deja atrás la noción sanguínea que introdujo Heródoto para amparar un posicionamiento supremacista cultural ${ }^{47}$. Naturalmente, la posición anterior quiere fijar una idea sencilla: las diversas comunidades e individuos pueden convertirse en griegos tras compartir una serie de valores (éticos, religiosos, culturales, linguiísticos) adquiridos a través de la educación $(\pi \alpha \iota \delta \varepsilon i ́ \alpha)^{48}$. Posteriormente, insiste sobre este asunto en Sobre el cambio de fortunas (= Antidosis) (354-53 a.C.) donde se plantea que la educación enaltece a los humanos frente a los animales y, como no, a los griegos frente a los bárbaros (Isoc. Antidosis 293) ${ }^{49}$.

$\mathrm{Al}$ abrigo de lo anterior, Isócrates redefine la noción de Europa a través de la educación y reduciendo en importancia la cuestión del linaje; todo ello con la intención de trasladar este nuevo modelo al macedonio Filipo. Dicho de otra forma, puede que Filipo no fuera griego pero no cabe duda de que era europeo, lo cual supone una vuelta de tuerca en la

44 Antes de la contienda final con Filipo en Queronea, tuvo lugar en Atenas un encendido debate entre los partidarios de Filipo, con Isócrates a la cabeza, y los detractores del mismo, liderados por Demóstenes. No menos intenso fue el debate sobre esta misma cuestión en la Europa de entreguerras lo cual puede seguirse, por ejemplo, en el Demostene e la libertà greca (1933) de Piero Treves y el Filippo il Macedone de Arnaldo Momigliano (1934). Años más tarde, Werner Jaeger también tomará posición en esta contienda en favor del orador Demóstenes (Jaeger 2017 [1938]).

45 Sobre este asunto véase el detallado análisis de Antela Bernárdez (2007).

46 En adelante seguimos la traducción de Guzmán Hermida, J. M. 2002: Isócrates. Discursos, Madrid: Gredos. En el texto anterior hemos tenido a bien traducir el sustantivo $\gamma \varepsilon ́ v o s$ por 'linaje' en lugar de 'raza' como propone el traductor.

47 De nuevo es importante remitir a la ‘oración fúnebre' de Pericles recogida en Tucídides (II. 35-46).

48 No sería una idea nueva pues Tucídices habla de regiones 'bárbaras' como Argos de Anfiloquia que, tras adoptar la lengua griega de sus vecinos, terminaron por helenizarse (Th. II. 68. 5; empleando el hápax iं $\lambda \lambda \eta v i ́ \sigma \theta \eta \sigma \alpha v)$; véase comentario en Hornblower $(1991,352)$.

49 Naturalmente una $\pi \alpha \iota \delta \varepsilon i ́ \alpha$ reservada a las élites, único sustrato social capaz de disponer del ocio y tiempo libre para formarse. Sobre este asunto, continúa siendo imprescindible Finley (1977 [1975], 299 ss.). 


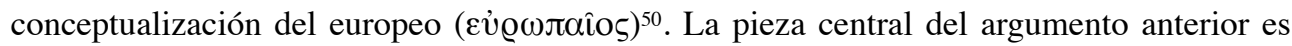
el Filipo (346 a.C.), que supone el apoyo explícito del maestro de retórica al macedonio emplazándolo a liderar la campaña panhelénica contra Asia ${ }^{51}$ :

Examina qué vergonzoso es permitir que Asia esté mejor que Europa, los bárbaros más prósperos que los griegos que, además, quienes heredan el poder de Ciro, a quien su madre dejó en un camino, se llamen grandes reyes, y, en cambio, los descendientes de Heracles, a los que su antepasado por su virtud puso entre los dioses, reciban nombres más humildes que aquellos. Nada de esto se puede permitir, sino que hay que derribar y cambiar todo lo que esté así.

Isoc. Filipo 132

El pasaje rememora muchos de los tópicos del pasado siglo $\mathrm{V}$ a.C. que postulan la existencia de dos bloques antagónicos. Sólo que aquí un rey, Filipo, viene a constituir la solución al problema. En otros términos, un monarca que se eleva por encima de la pólis para emprender la inveterada empresa panhelénica. Con todo, unos renglones más adelante aún se precisa más el papel de Filipo en la contienda Asia/Europa:

[...] ya que tú has adquirido tanta fuerza como ninguno de los que habitaron Europa y lucharás contra un individuo odiado y despreciado por todos como ningún otro de los que antes reinaron.

Isoc. Filipo 137

Considerando ambos testimonios se aprecia la intención de situar a Filipo a la cabeza de Europa, hecho insólito, para liderar Grecia hacia la victoria contra el bárbaro (asiático) ${ }^{52}$. No nos cabe duda de que Isócrates trata de solventar a nivel teórico los problemas que podían surgir para aceptar la hegemonía macedonia. El proceso puede resumirse en dos vías: 1) Filipo se heleniza en virtud de su educación y proximidad a la cultura griega y 2) se edulcora la posibilidad de un dominio macedonio bajo el subterfugio de un Filipo europeo ${ }^{53}$. Por su parte Teopompo de Quíos, según testimonio de Polibio, seguirá la misma línea que su maestro, afirmando que Europa no habrá producido un hombre de la talla política de

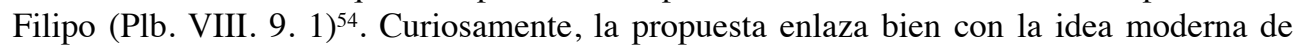

50 En la corte macedónica conocían el griego y sus monarcas insistían en recalcar sus orígenes helénicos pero, desde la cultura política griega, se les consideraba bárbaros especialmente por sus costumbres y organización política. Amplíese esta cuestión en Pina Polo (1993, 165).

51 En detrimento de Atenas que, según Isócrates, había fracasado en dicha empresa.

52 El historiador y discípulo de Isócrates, Teopompo de Quíos, abundará en esta cuestión en su Filípica; obra en origen extensa sobre la cual conservamos fragmentos; en general, (Shrimpton 1991).

53 En contraposición tenemos las duras críticas del orador ateniense Demóstenes, quien califica a Filipo de bárbaro en las Terceras filípicas (30-31); forma parte del debate que señalábamos anteriormente.

54 Notemos que la cita de Polibio es directa: Teopompo es quien, desde esta perspectiva, merece una reprensión más dura, porque al principio de su Historia de Filipo II de Macedonia afirma que le ha espoleado a emprender su tarea el hecho de que Europa no ha producido nunca un hombre como Filipo hijo de Amintas. (Plb. VIII. 9; trad. Balasch, M. 2000: Polibio. Historia, Madrid: Gredos). El término anotado en el texto (Ev̉@órๆ) denota todavía una realidad geográfica reducida a la Grecia continental pero confiere a Filipo la etiqueta de figura política europea, evitando la controversia alrededor del término "E $\lambda \lambda \eta v o \zeta$; todo el pasaje se enmarca en 
una Europa que supera los estados nación aunque, obviamente, la intención de Filipo no era liderar una coalición de póleis libres contra Persia sino someter Grecia. Puede entenderse, con Momigliano, que este concepto político tuvo una vida breve al percatarse Isócrates de la nula intención del monarca de ponerse al frente de Europa ${ }^{55}$. Ello puede seguirse en Panatenaico (339 a.C.) donde se retorna al liderazgo de Atenas.

Concluyendo, la idea de Europa experimenta un largo y tortuoso camino adquiriendo valores y significados muy diversos (mitología, geografía, prejuicios culturales, etc) hasta recibir en Isócrates una redefinición política. En este sentido, a nivel teórico el rétor trata de superar el marco de la pólis para conferir un talante europeísta al rey de macedonia ${ }^{56}$. Con todo, resulta especialmente interesante apreciar cómo detrás del ejercicio teórico subyace la

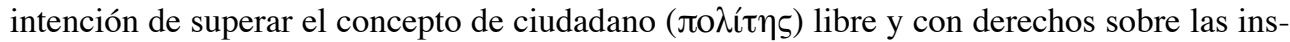
tituciones políticas para introducir a la pólis bajo un concepto de estado imperial. Asimismo, el planteamiento de Isócrates soslaya la espinosa cuestión que introduce el escrito hipocrático Aires aguas y lugares: la relación entre climatología y formas de gobierno. Siguiendo esta ecuación, la monarquía no sería una forma de gobierno propia de Europa debido a un clima que favorecería la existencia de hombres aguerridos y amantes de la libertad. Este razonamiento cae del Filipo por razones evidentes ${ }^{57}$.

Los griegos no concebían una Europa capaz de integrar las diferentes póleis en un proyecto político y, por ello, la efímera propuesta de Isócrates construyó una precaria identidad europea alrededor de Filipo; pero todo ello no debe hacernos apartar la mirada sobre la inexistencia de una auténtica política europea. En cierto modo, podemos afirmar que, a nivel político, las raíces griegas de la actual Europa sólo quedan en el nombre.

\section{Bibliografía}

Albaladejo, M. (2005), «Los extremos de Europa en la obra de Píndaro y Heródoto», Klio 87 (2), pp. 315-328.

Albaladejo, M. (2007), «La imagen de los pueblos lejanos en la obra de Heródoto», BAEO 43 pp. 267-281.

Antela Bernárdez, B. (2007), «Hegemonía y Panhelenismo: conceptos políticos en tiempos de Filipo y Alejandro», DHA 33(2), pp. 69-89.

una acerada crítica de Polibio hacia las cualidades de Teopompo como historiador; $v$. Momigliano 1984 [1931]: 187-188. Similares anotaciones encontramos en Diodoro de Sicilia, cuando sostiene que Filipo consiguió el reino más potente de Europa (Diod. XVI. 1.3 y 5.4) pero no resulta claro que el argumento proceda de Teopompo, habida cuenta que las fuentes de la Biblioteca histórica son variadas y complejas de individuar. Por ejemplo, para este periodo y siempre alrededor de la figura de Filipo, cita como fuentes: Diílo de Atenas (Diod. XVI. 75. 6), Teopompo (Diod. XVI. 3.8) o, para algunos datos, Timeo de Tauromenio (Diod. XVI. 7. 1). Sobre la Quellenforschung en Diodoro resulta útil la obra de Sacks 1990.

55 Naturalmente la idea en la Europa de entreguerras posee un valor político totalmente contemporáneo; $v$. Momigliano (1966 [1933], 497).

56 Nada más lejos de la realidad dado que el macedonio venía a socavar la libertad política griega. Aquí discrepamos con Arnaldo Momigliano, que sugiere que Filipo condujo a Grecia hacia nuevas cotas de libertad: Momigliano $(1934,50)$.

57 Cabe conjeturar que Isócrates conocía el determinismo climático dado que se documenta en Heródoto, Jenofonte, Platón o Aristóteles. Luego se trataría de una omisión intencionada. En general, sobre el determinismo climático véase Borca (2003) y Sierra $(2019,10)$. 
Asheri, D.; Lloyd, A.; Corcella, A. (2007), A Commentary on Herodotus Books I-IV, Oxford: Oxford University Press.

Bernabé, A. (2001), «Introducción», en: Himnos homéricos. La 'Batracomiomaquia', Madrid: Gredos, pp. 53-73.

Borca, F. (2003), Luoghi, corpi, costumi: determinismo ambientale ed etnografia antica. Roma: Edizioni di Storia e Letteratura.

Chang, H. (2005), «The Cities and the Hippocratic doctors», en: van der Eijk, Ph. (ed.). Hippocrates in context. Papers read at the XIth International Hippocrates Colloquium. University of Newcastle upon Tyne, 27-31 August 2002. Leiden: Brill, pp. 157-171.

Cortés Copete, J. M. (2005), «Polis romana. Hacia un nuevo modelo para los griegos del imperio», SSHA 23, pp. 413-437.

Finley, M. I. (1977 [1975]), «El legado de Isócrates», en: Uso y abuso de la historia, Barcelona: Crítica, pp. 295-328.

Fowler, R. L. (2001), «Early Historiē and Literacy», en: Luraghi, N. (ed.), The Historian's Craft in the Age of Herodotus, Oxford: Oxford University Press, pp. 95-115.

Gómez Espelosín, F. J. (2000), El descubrimiento del mundo. Geografía y viajeros en la antigua Grecia, Madrid: Akal.

Gómez Espelosín, F. J. (2013), Memorias perdidas. Grecia y el mundo oriental, Madrid: Akal.

Grethlein, J. (2009), «How to Do History: Xerxes in Herodotus' "Histories"”, AJPh 130(2), pp. 195-218.

Hall, J. M. (2002), Hellenicity: between ethnicity and culture, Chicago: University of Chicago Press.

Harris, W. V. (2009), Dreams and Experience in Classical Antiquity, Cambridge (Mass.): Harvard University Press.

Hermosa, A. (2019), «La antropología de la democracia. El demócrata en la 'Oración fúnebre’ de Pericles», en: Fornis, C.; Hermosa, A.; Fernández, J. (eds.), Tucídides y el poder de la historia, Sevilla: Publicaciones de la Universidad de Sevilla, pp. 123-138.

Hornblower, S. (1991), A Commentary on Thucydides, v. 1, Oxford: Oxford University Press.

Isaac, B. (2004), The Invention of Racism in Classical Antiquity, Princeton: Princeton University Press.

Jaeger, W. (2017 [1938]), Demóstenes, México: Fondo de Cultura Económica.

Jouanna, J. (1996), «Notice», En: Hippocrate. Airs, Eaux, Lieux, Paris: Les Belles Lettres (CUF). 7-173.

Laín Entralgo, P. (1982 [1970]), La medicina hipocrática, Madrid: Alianza.

Liddell, H. G.; Scott, R. (1996), A Greek English Lexicon, Oxford: Clarendon Press.

Lloyd, G. E. R. (2008 [2002]), Las aspiraciones de la curiosidad. La comprensión del mundo en la antigüedad: Grecia y China, Madrid: Siglo XXI.

López Ferez, J. A. (1984), «Pronóstico y terapia en el tratado hipocrático « Sobre los aires, aguas y los lugares ». Unidad de escrito», Epos, 1, pp. 103-118.

Marincola, J. (2001), Greek Historians, G\&R New Surveys in the Classics 31, Oxford: Oxford University Press.

Mas S. (2003), Ethos y Pólis. Una historia de la filosofía práctica en la Grecia clásica, Madrid: Istmo. 
Mazzarino, S. (1989 [1947]), Fra Oriente e Occidente. Ricerche di Storia greca arcaica, Milán: Rizzoli.

Momigliano, A. (1934), Filippo il Macedone. Saggio sulla storia greca del IV secolo a.C., Milano: Guerini e Associati.

Momigliano, A. (1966[1933]), «L'Europa come concetto politico presso Isocrate e gli isocratei», en: Terzo contributo alla storia degli studi classici e del mondo antico, v. 1, Roma, pp. 489-498.

Momigliano, A. (1984[1931]): “Teopompo”, en: La historiografía griega, Barcelona: Crítica, pp. 168-194.

O'Connor, D. K. (2011), «Xenophon and the Enviable Life of Socrates», en: Morrison, D. R. (ed.), The Cambridge Companion to Socrates, Cambridge: Cambridge University Press, pp. 48-74.

Pina Polo, F. (1993), «El ascenso y la hegemonía de Macedonia: características del régimen monárquico», Polis 5, pp. 163-185.

Plácido, D. (2007), «Las formas del poder personal: la monarquía, la realeza y la tiranía», Gerión 25(1), pp. 127-166.

Plácido, D. (2017), La crisis de la ciudad clásica y el nacimiento del mundo helenístico, Buenos Aires: Miño y Dávila.

Quesada Sanz F. (2008), «Filosofía y política: la institución de la democracia», en: Quesada Sanz, F. (ed.), Ciudad y ciudadanía. Senderos contemporáneos de la filosofía política, Madrid: Trotta, pp. 89-118.

Rodríguez Adrados, F. (2000), «Introducción general», en: Esquilo. Tragedias, Madrid: Gredos, pp. ix-xxxviii.

Romm, J. (1992), The Edges of the Earth in Ancient Thought, Princeton: Princeton University Press.

de Romilly, J. (1992), «Isocrates and Europe», Greece and Rome 39(1), pp. 2-13.

Sacks, K. (1990), Diodorus Siculus and the First Century, Princeton: Princeton University Press.

Samama, E. 2003: Les médecins dans le monde grec. Sources epigraphiques sur la naissance d'un corps médical, Genève: Droz.

Santiago, R. A. (1998), «Griegos y bárbaros: arqueología de una alteridad», Faventia 20 (2), pp. 33-45.

Shrimpton, G. S. (1991), Theopompus the Historian, Montreal: McGill-Queen's University Press.

Sierra, C. (2018), «Díaita: estilo de vida y alteridad en el Sócrates de Jenofonte», Logos 51, pp. $305-326$

Sierra, C. (2019), «Historia y medicina: una breve introducción», en: Sierra, C.; Antela, B. (eds.), Historia y medicina en la antigüedad, Zaragoza: Pórtico, pp. 1-15.

Treves, P. (1933), Demostene e la libertà greca, Bari: Laterza.

Zacharia, K (2008), «Herodotus' Four Markers of Greek Identity», en: Zacharia, K. (ed.), Hellenisms: Culture, Identity, and Ethnicity from Antiquity to Modernity, Hampshire: Ashgate, pp. 21- 36. 